\title{
High-latitude propagation studies using a meridional chain of $\mathrm{LF} / \mathrm{MF} / \mathrm{HF}$ receivers
}

\author{
J. LaBelle \\ Department of Physics and Astronomy, Dartmouth College, Hanover, New Hampshire, USA \\ Received: 12 August 2003 - Revised: 6 January 2004 - Accepted: 14 January 2004 - Published: 8 April 2004
}

\begin{abstract}
For over a decade, Dartmouth College has operated programmable radio receivers at multiple high-latitude sites covering the frequency range $100-5000 \mathrm{kHz}$ with about a 1-s resolution. Besides detecting radio emissions of auroral origin, these receivers record characteristics of the ionospheric propagation of natural and man-made signals, documenting well-known effects, such as the diurnal variation in the propagation characteristics of short and long waves, and also revealing more subtle effects. For example, at auroral zone sites in equinoctial conditions, the amplitudes of distant transmissions on MF/HF frequencies are often enhanced by a few $\mathrm{dB}$ just before they fade away at dawn. The polarization and/or direction of the arrival of ionospherically propagating signals in the lower $\mathrm{HF}$ range $(3-5 \mathrm{MHz})$ show a consistent variation between pre-midnight, post-midnight, and pre-dawn conditions. As is well known, magnetic storms and substorms dramatically affect ionospheric propagation; data from multiple stations spanning the invariant latitude range $67-79^{\circ}$ reveal spatial patterns of propagation characteristics associated with magnetic storms and substorms. For example, in the hours preceding many isolated substorms, favorable propagation conditions occur at progressively lower latitudes as a function of time preceding the substorm onset. For some of these effects, explanations follow readily from elementary ionospheric physics, but understanding others requires further investigation.
\end{abstract}

Key words. Magnetospheric physics (annual phenomena) Radio science (ionosphere propagation; radio-wave propagation)

\section{Introduction}

For over a decade, Dartmouth College has operated programmable radio receivers at high-latitude sites, in an effort to systematically study radio emissions of auroral origin (see reviews by LaBelle and Weatherwax, 1992; LaBelle and Treumann, 2002). These same receivers provide a wealth of

Correspondence to: J. LaBelle

(jlabelle@einstein.dartmouth.edu) information on the propagation characteristics of man-made and natural signals at frequencies from $100 \mathrm{kHz}$ to $5 \mathrm{MHz}$. The man-made signals in this frequency range include navigational beacons at a few hundred kilohertz, AM broadcast transmissions at $535-1600 \mathrm{kHz}$, and short-wave transmissions at $1600-5000 \mathrm{kHz}$. Natural signals include atmospherics and auroral radio emissions. Measurements of these signals illustrate a number of propagation effects, some of which are well known, but others of which have not been previously documented.

Section 2 describes the programmable radio receivers used in this study, and Sections 3-5 present examples of propagation effects observed that are associated with diurnal patterns, the dawnside terminator, and magnetic storms and substorms.

\section{Instrumentation}

The receivers used in this study involve one of two antenna types: electric or magnetic dipoles. In both cases, the antenna is nonresonant at all frequencies detected. The electric dipole consists of a $3 \mathrm{~m}$ vertical rod elevated approximately $3 \mathrm{~m}$ above the ground. The magnetic dipole consists of a $10-\mathrm{m}^{2}$ magnetic loop antenna oriented vertically at an angle which nulls out the strongest local interference signal. In both cases, active preamplifiers at the antenna couple the signals to coaxial cables for transmission to the receiver in a building several hundred feet away.

The programmable receiver used in this study is described in detail by Weatherwax (1994) and Weatherwax et al. (1995). Although its frequency schedule, frequency resolution, and time resolution are fully programmable, in practice the receiver has usually been programmed to execute 0.05-5 MHz sweeps each 1-2 s with $10 \mathrm{kHz}$ resolution. Most of the time, the receiver operates 20-24h/day, skipping up to $4 \mathrm{~h}$ around local noon for housekeeping purposes. The data are digitized and archived on CD-ROMs. Operators at the remote sites change disks at 2-4 week intervals and mail the data to Dartmouth College, where survey plots are generated. 
Table 1. Northern Hemisphere locations of LF/MF/HF receivers.

\begin{tabular}{cccc}
\hline site & geogr. coord. & inv. lat. & 00:00 MLT \\
\hline Gillam & $56.38 \mathrm{~N}, 265.36 \mathrm{E}$ & 66.57 & $06: 36 \mathrm{UT}$ \\
Churchill & $58.76 \mathrm{~N}, 265.36 \mathrm{E}$ & 68.83 & $06: 37 \mathrm{UT}$ \\
Arviat & $61.11 \mathrm{~N} 265.92 \mathrm{E}$ & 71.09 & $06: 36 \mathrm{UT}$ \\
Baker Lake & $64.32 \mathrm{~N}, 263.97 \mathrm{E}$ & 73.89 & $06: 51 \mathrm{UT}$ \\
Taloyoak & $69.54 \mathrm{~N}, 266.45 \mathrm{E}$ & 78.85 & $06: 45 \mathrm{UT}$ \\
Resolute Bay & $74.72 \mathrm{~N}, 265.03 \mathrm{E}$ & 83.31 & $07: 18 \mathrm{UT}$ \\
Fairbanks & $64.80 \mathrm{~N}, 212.30 \mathrm{E}$ & 65.01 & $11: 10 \mathrm{UT}$ \\
Circle Hot Spgs & $65.50 \mathrm{~N}, 215.30 \mathrm{E}$ & 66.27 & $10: 36 \mathrm{UT}$ \\
Sondrestrom & $66.99 \mathrm{~N}, 309.05 \mathrm{E}$ & 73.09 & $02: 21 \mathrm{UT}$ \\
\hline
\end{tabular}

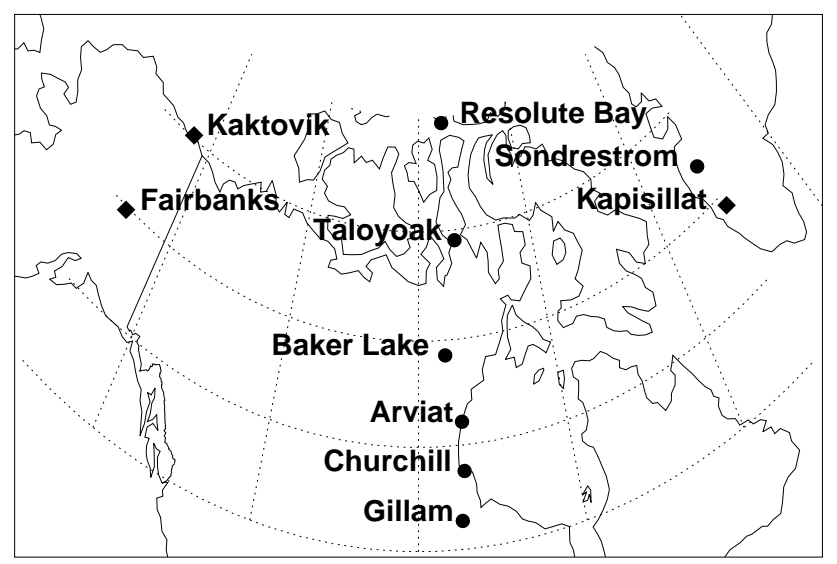

Fig. 1. Map showing locations of Northern Hemisphere LF/MF/HF receivers.

In principle, this receiving system can detect signals as weak as $5 \mathrm{nV} / \mathrm{m} \sqrt{\mathrm{Hz}}$, but in practice sensitivity is usually limited to several times that threshold by the environmental background noise, even at the most remote sites. Always some frequencies are occupied by local fixed-frequency transmissions, and at many sites, notch filters attenuate these signals at the front end of the receiver so that gain can be applied in order to bring weak signals into the range of the receiver's sensitivity. The dynamic range of the receiver is about $70 \mathrm{~dB}$; the dynamic range of the preamplifier exceeds $90 \mathrm{~dB}$.

Receiver systems, like that described above, have been operated from: Two Rivers and Circle Hot Springs, Alaska; Gillam and Churchill, Manitoba; Arviat, Baker Lake, Taloyoak, and Resolute Bay, Nunavut; and Sondre Stromfjord, Greenland. The locations and magnetic latitudes of these sites are summarized in Table 1. Figure 1 shows these locations on a map of North America. Similar receiver systems have been operated at some Southern Hemisphere sites.

At Churchill during 1997-1998, two magnetic loop antennas in the vertical plane oriented perpendicular to each other were deployed, and the phase between them recorded at each frequency, to determine wave polarization as described

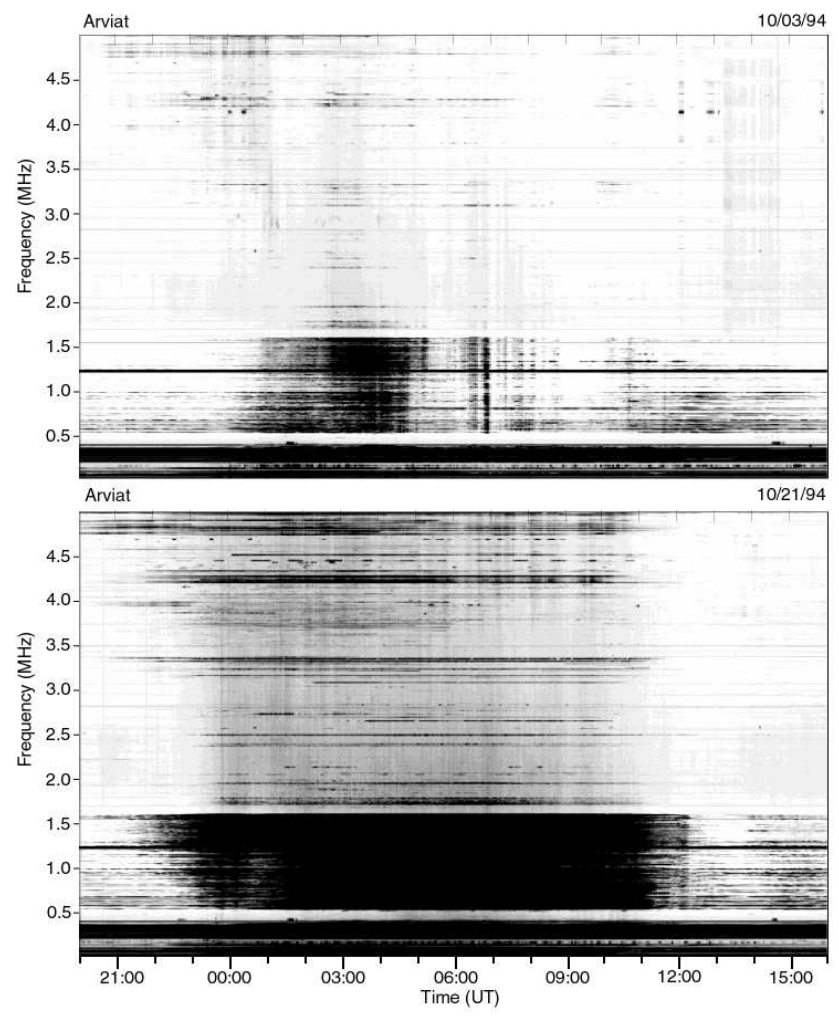

Fig. 2. $50-5000 \mathrm{kHz}$ spectrograms recorded at Arviat, Nunavut, on: (a) 3-4 October 1994, the most disturbed day of the month on which $\Sigma K p=48$; and (b) 21-22 October 1994, the geomagnetically quietest day of the month on which $\Sigma K p=6$. White (black) pixels represent psd below (above) $6 \times 10^{-9} \mathrm{~V} / \mathrm{M} \sqrt{(\mathrm{Hz})} 3 \times 10^{-7}$ $\mathrm{V} / \mathrm{M} \sqrt{(\mathrm{Hz})})$.

by Shepherd et al. (1997), who used this method to determine polarization of radio emissions of auroral origin. The phase difference between the antennas effectively separates left- from right-elliptically polarized waves, provided that the waves arrive from near the zenith; for waves arriving at low elevation angles, the determination of the handedness of the polarization is less effective. Detection of the polarization of whistler mode auroral hiss, which is known to be right-hand polarized, confirms that the technique works (Shepherd et al., 1997).

\section{Diurnal variations of propagation characteristics}

Figure $2 \mathrm{~b}$ shows the $0-5 \mathrm{MHz}$ radio spectrum recorded at Arviat, Northwest Territories, during a 20-h interval, starting on 21 October 1994, a geomagnetically quiet day ( $\Sigma K_{p}=6+$ : the quietest day in October, 1994). Geographic local midnight occurs at 06:16 UT; midnight magnetic local time (MLT) occurs at 06:36 UT. The power spectral density of the received signals is encoded in a gray scale, with white pixels representing power spectral densities (PSD) below $6 \times 10^{-9} \mathrm{~V} / \mathrm{m} \sqrt{\mathrm{Hz}}$ and black pixels representing PSD exceeding $32 \mathrm{~dB}$ above this level. Horizontal lines represent 


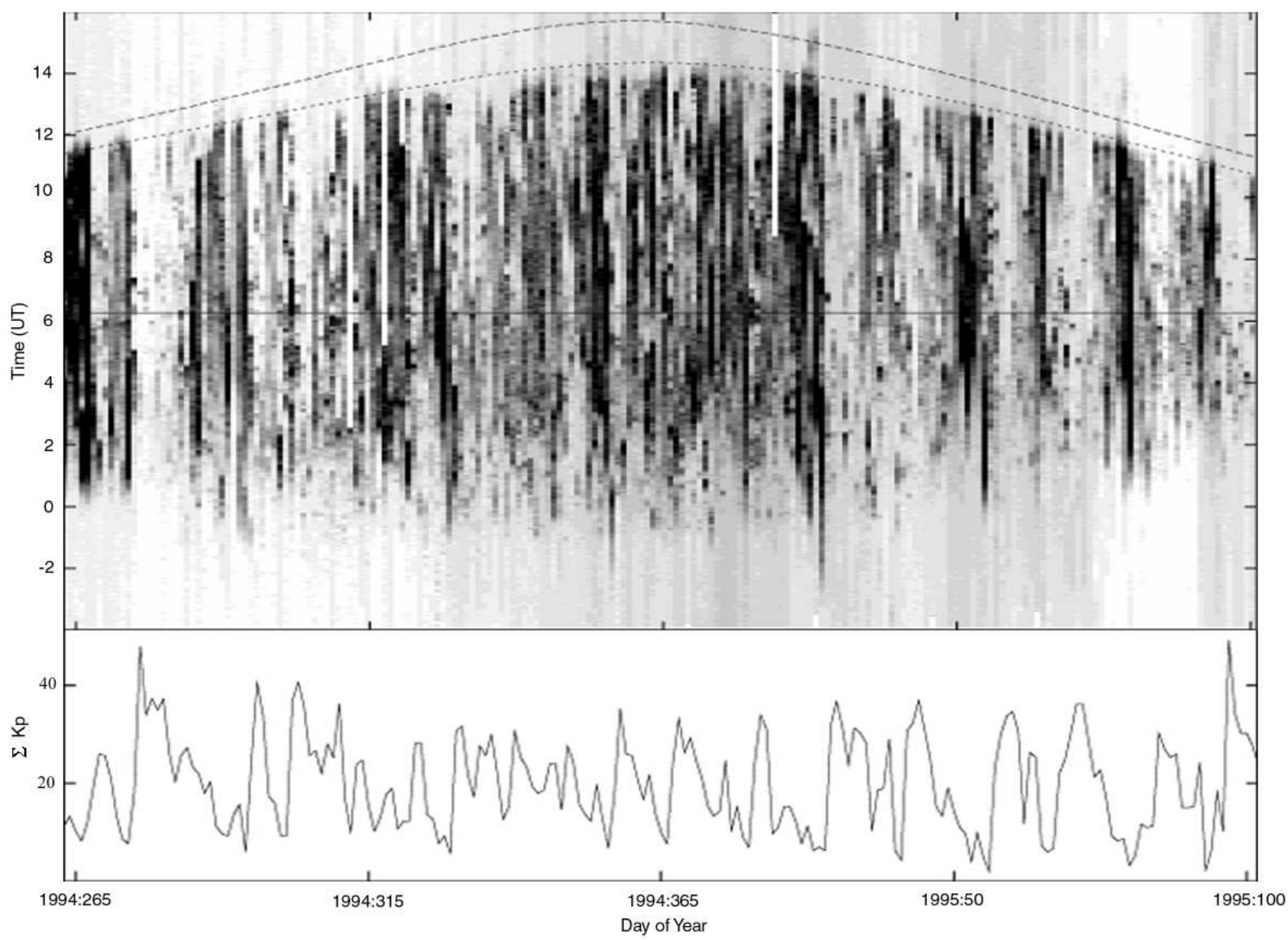

Fig. 3. Six months of radio propagation data recorded at Arviat, Nunavut. The horizontal axis is day of year starting on day 263 of 1994 and ending on day 102 of 1995. The vertical axis represents 20:00-16:00 UT; geographic local midnight corresponds to 06:16 UT, near the center of the plot. The received radio frequency power integrated over the frequency range $550-1600 \mathrm{kHz}$, corresponding to the AM broadcast band, is encoded in the gray scale, with white (black) pixels corresponding to integrated rms amplitudes below $0.3 \mathrm{mV} / \mathrm{m}$ (above $4 \mathrm{mV} / \mathrm{m}$ ). The upper long-dashed line represents the time of sunrise at ground-level at Arviat, and the lower short-dashed line represents the time of sunrise $250 \mathrm{~km}$ south of Arviat at an altitude of $80 \mathrm{~km}$, using grazing incidence at $55 \mathrm{~km}$ to define sunrise. The lower panel displays daily sum $K p$ index smoothed with a 7-day running average.

fixed-frequency transmissions, and many such transmissions are observed in the AM broadcast band $(550-1600 \mathrm{kHz})$. Another band of transmissions below $400 \mathrm{kHz}$ consists of navigational beacons, and fixed frequency signals are also seen in the short-wave bands above $1600 \mathrm{kHz}$. The more or less uniform gray background, particularly visible at 1600 $5000 \mathrm{kHz}$, consists primarily of large numbers of atmospherics generated at great distances by lightning; the individual spherics cannot be discerned because the spectra displayed in Fig. $2 b$ have been averaged over several minutes.

The most obvious and best-known feature of the radio spectrum at $\mathrm{MF} / \mathrm{HF}$ is the diurnal variation of the intensity of signals propagating from distant sources to the reception site. At frequencies above a few hundred $\mathrm{kHz}$, the propagation of both natural and man-made radio signals from distant sources is enhanced at night, when D-region absorption is absent. The only exceptions to this observation are the lowest frequency signals at $200-400 \mathrm{kHz}$ and local AM transmitters such as that at $1240 \mathrm{kHz}$, whose reception is insensitive to ionospheric conditions.

At dusk ( 22 UT), the highest frequency signals within the AM broadcast band show the switch from daytime to nighttime propagation conditions as early as 21:00 UT, but lower frequency signals continue to experience the Dregion absorption typical of daytime conditions until almost 23:00 UT. This pattern usually reverses itself at dawn, with lower frequency signals affected earlier than higher frequency signals by the increasing D-region ionization caused by the rising Sun.

Figure 2a shows a similar $0-5 \mathrm{MHz}$ radio spectrum observed at Arviat on 3 October 1994, a geomagnetically disturbed day ( $\Sigma K_{p}=48$, the most disturbed day in October, 1994). The format and gray scale are identical to those of Fig. 2b. The dusk and dawn terminators are not much different on 3 October than they are on 21 October. However, the diurnal pattern which dominates the quiet day spectrum 


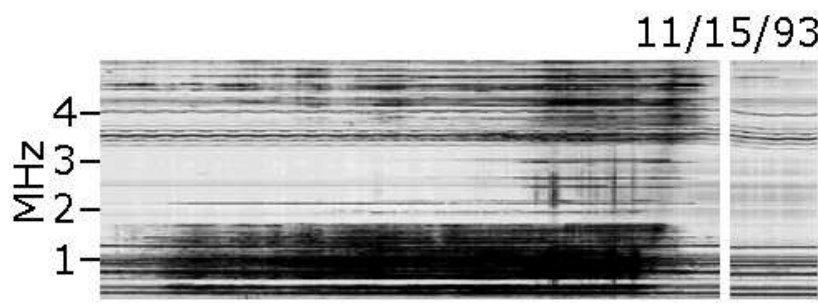

$10 / 7 / 93$

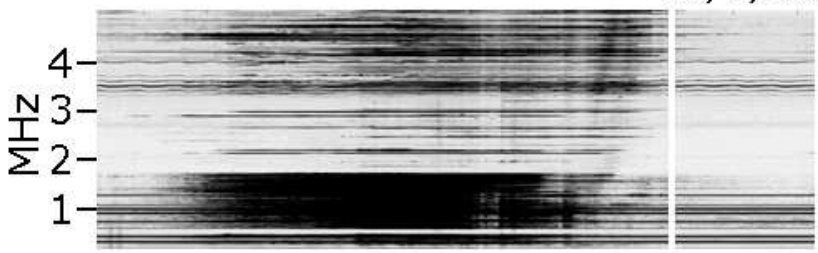

$10 / 5 / 93$

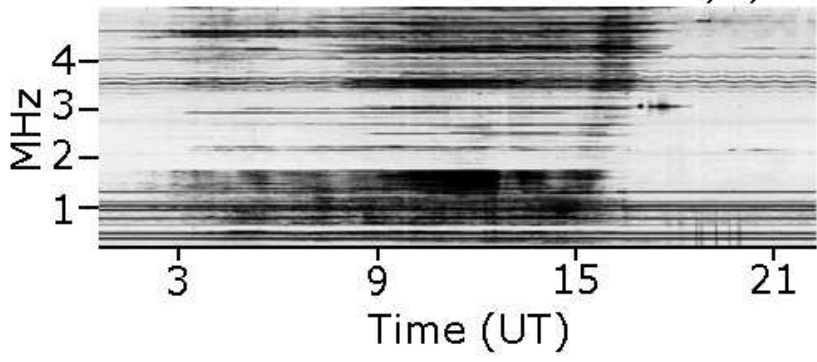

Fig. 4. 50-5000 kHz spectrograms recorded at Circle Hot Springs, Alaska, 7 October, 5 October, and 15 November 1993. White pixels represent PSD below $10^{-8} \mathrm{~V} / \mathrm{m} \sqrt{\mathrm{Hz}}$ and black pixels represent PSD exceeding $10^{-7} \mathrm{~V} / \mathrm{m} \sqrt{\mathrm{Hz}}$. Received LF/MF/HF transmissions are enhanced in amplitude for about one hour just before sunrise, after which they are sharply attenuated. As with the attenuation, the enhancement occurs first at the lowest frequencies, then shifts to higher frequencies.

is severely disrupted on the disturbed day. Except for a few hours before local midnight (00-05 UT) and a few isolated intervals after local midnight, distant AM broadcast transmissions at $550-1600 \mathrm{kHz}$ and atmospherics from distant lightning are observed at intensities typical of daytime conditions. Even shortwave signals at frequencies 3-5 MHz are of much lower intensity than on magnetically quiet nights. The signals which are detected exhibit episodes of prompt attenuation; often these episodes are related to magnetic substorms (e.g. LaBelle et al., 1994), in which case this phenomenon is called substorm correlated absorption of ionospherically propagating signals (e.g. see Milan et al., 1996).

Hunsucker and Bates (1969) reviews effects of auroral activity on ionospheric propagation such as non-great-circle propagation, auroral sporadic E-layer propagation, $\mathrm{F}_{1}$-layer effects, D-region absorption, and scattering by ionospheric irregularities. The enhanced absorption of ionospherically propagating natural and man-made signals during times of high geomagnetic activity shown in Fig. 2a probably results from expansion of the auroral oval to regions south of the high-latitude observing sites, implying strong auroral activity between the receiver and the sources of the natural and man-made signals, which generally originate far south of Arviat. The auroral precipitation causes low-altitude ionization, which mimics the propagation characteristics of the daytime ionosphere. The normal diurnal pattern is then disrupted, as observed on 3 October 1994. As shown in Fig. 2a, the D-region absorption associated with the auroral activity is usually less continuous in nature than that associated with photoionization. Figure $2 \mathrm{a}-\mathrm{b}$, in fact, closely parallel Figs. 6-7 in Hunsucker et al. (1985) which show the impact of auroral activity on reception at Fairbanks, Alaska, of multiple individual AM broadcast stations originating in the continguous United States. At times ionospheric propagation on some paths is enhanced rather than diminished by auroral activity, although Fig. 2a shows no obvious example of this phenomenon, an effect which may be partly attributed to propagation via an enhanced auroral E-layer, as documented by several investigators (e.g. Hunsucker and Bates, 1969; Hunsucker et al., 1996; Milan et al., 1997).

The diurnal variation of ionospheric propagation characteristics can be parameterized by integrating the power spectral density over a selected band, such as the AM broadcast band $(550-1600 \mathrm{kHz})$. Figure 3 a shows this integrated power, encoded into a gray scale, as a function of local time for a six-month period, September 1994 through April 1995. Local time is on the vertical axis, with geographic local midnight (06:16 UT) near midscale, indicated by a solid line. In Fig. 3a, the normal diurnal pattern of the propagation characteristics of AM signals is quite clear: the signals are intense at night (middle of the figure) and weak during the day (top and bottom edges of the figure). The seasonal variation in the local time of the terminator is obvious, as daytime conditions set in more than two hours later at solstice (day 355, near the middle of the plot) than at the equinoxes. Of course, many AM broadcast stations vary the power and directionality of their signals with the time of day, and this artificial variation may also contribute to the diurnal and seasonal variations of signals received at Arviat shown in Fig. 3.

A striking asymmetry between the dawn and dusk terminators appears: the dawn terminator forms a sharper transition between daytime and nighttime propagation conditions than does the dusk terminator. This observation may be explained qualitatively by the different time constant for prompt formation of the D- and E-regions after the onset of photoionization at sunrise versus the decay of the D- and E-regions after sunset.

The upper long-dashed line in Fig. 3a shows the local time of sunrise at Arviat, as a function of day of year between September 1994 and April 1995. This sunrise occurs considerably after the transition in propagation characteristics, as expected, since the propagation characteristics react to the sunrise at D- and E-region heights which occurs earlier than sunrise at ground level. Furthermore, the difference between the local times of sunrise at solstice versus equinox at Arviat does not match that of the transition in propagation characteristics inferred from the radio spectral observations. The observed boundary is not bowed strongly enough; that is, the local time of the day/night transition at solstice does not 
differ as much from that at equinox as it should, were it associated with the local sunrise and sunset at Arviat. This effect is also not surprising, because the signals, which reach the receiver at Arviat by skipping off of the ionosphere, transit the D- and E-regions and suffer absorption at a latitude different from Arviat. The bulk of the sources come from south of Arviat, so the observed pattern in the day/night radio propagation boundary should match the times of sunrise and sunset at a latitude equatorward of Arviat, where the equinoxsolstice difference is smaller, in qualitative agreement with the data.

A further subtlety arises because the sunrise or sunset at Dregion altitude must be calculated based on sunlight making a grazing angle not at ground level but at an altitude above about $50 \mathrm{~km}$, because the initial increase (decrease) in electron density at D-region altitudes at sunrise (sunset), affecting radio propagation, is due to the breakup of negative ions which dominate the nighttime D-region, and the dominant negative ions in the nighttime D-region require UV rather than visible light for breakup. This was discovered long ago from modelling radio propagation effects near the terminator during polar cap absorption (PCA) events (Reid, 1961), as reviewed by Rishbeth and Garriott (1969), Reid (1976), and others. The lower short-dashed line shows the time of sunrise at an altitude of $80 \mathrm{~km}$, at a distance $250 \mathrm{~km}$ south of Arviat, defining sunrise by the ray from the Sun tangent to the Earth at $55 \mathrm{~km}$ altitude. The fit is excellent; in contrast, defining sunrise by the ray tangent to the Earth produces a poor fit at all reasonable altitudes and distances from Arviat. These data therefore confirm the predominance in the nighttime Dregion of negative ions that require UV for breakup, such as $\mathrm{NO}_{3}$, rather than negative ions which are detached by visible light. In this case the propagation data come not from PCA events but from daily sunrise/sunset events over the course of six months.

Figure $3 \mathrm{~b}$ plots the daily $\Sigma K_{p}$ index between September 1994 and April 1995, smoothed by a seven-day running average, showing how high-latitude reception of distant AM broadcast band transmissions depends on geomagnetic activity. Several-day periods of high $\Sigma K_{p}$ are correlated oneto-one with intervals when the integrated power in the AM broadcast band is almost as weak at night as it is during the day. The latter intervals appear as light vertical bands in Fig. 3a. Also evident in Fig. 3a is the tendency of the distinct geomagnetic storms to occur at 27-day intervals and favor the equinoxes, a pattern associated with magnetic storms during the solar minimum conditions.

The effects shown in Figs. 2-3 are mostly well known, and the six-month parameterization of the propagation data shown in Fig. 3 makes a particularly effective textbook demonstration of them. We now turn to more subtle features, some not previously documented.
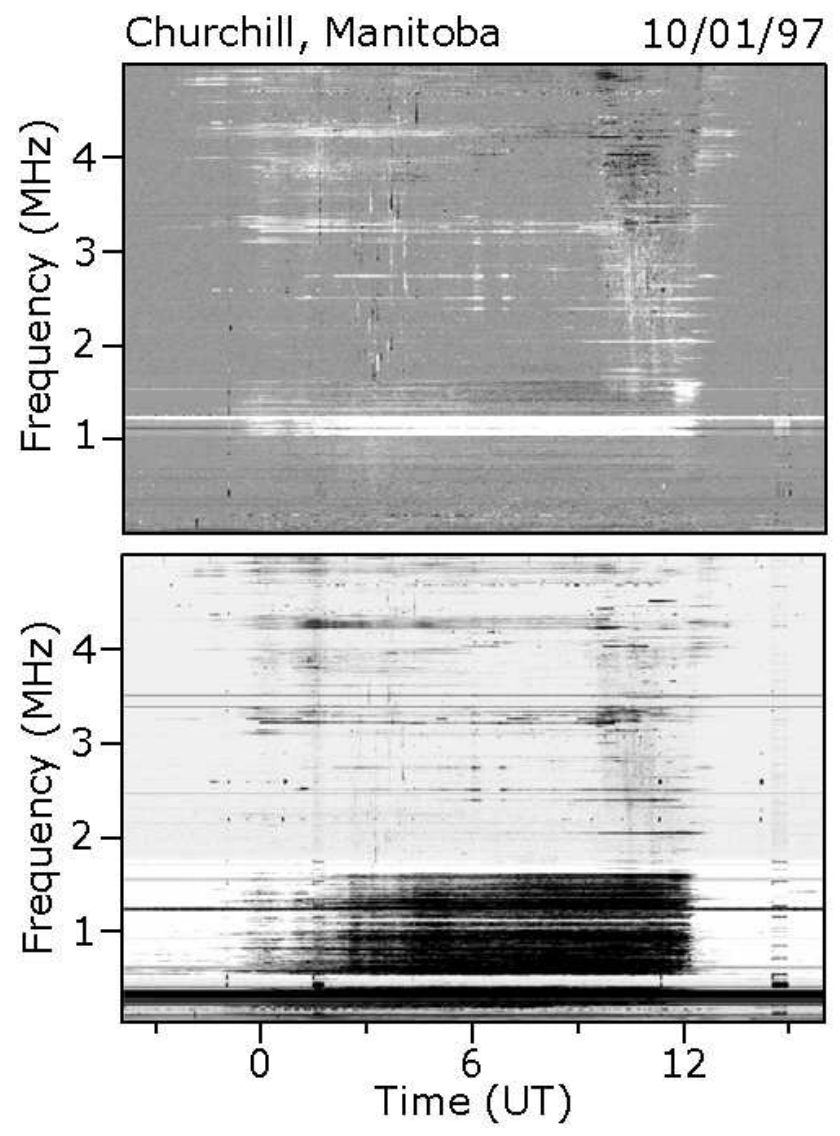

Fig. 5. (a) Polarization of $50-5000 \mathrm{kHz}$ signals recorded at Churchill, Manitoba, on 1-2 October 1997. White pixels indicate left-hand polarization, black pixels indicate right-hand polarization, and gray pixels indicate indeterminant polarization. (b) Power spectral density of the same $50-5000 \mathrm{kHz}$ signals. Received signals above $1 \mathrm{MHz}$ are predominantly left-hand polarized except in the interval 09:00-12:00 UT, 1-4h before sunrise, when righthand waves dominate at frequencies above about $3 \mathrm{Mhz}$.

\section{Terminator effects on radio-wave propagation}

Figure 4 shows three examples of an $\mathrm{MF} / \mathrm{HF}$ propagation phenomenon occurring near sunrise. Each panel shows $22 \mathrm{~h}$ of data, corresponding to 00:00-22:00 UT, recorded at Circle Hot Springs, Alaska, on 5 October, 7 October, and 15 November 1993. The vertical axis covers $0.1-4.8 \mathrm{MHz}$, and the gray scale covers a $20-\mathrm{dB}$ range in PSD, from $10^{-8}$ to $10^{-7} \mathrm{~V} / \mathrm{m} \sqrt{\mathrm{Hz}}$. All three of these days correspond to geomagnetically quiet conditions. Typical of quiet conditions, the received AM broadcast band and shortwave signals have greater amplitude at night than during the day, with the exception of local AM stations, beacons, and interference. The frequency modulated signals at $3.2-3.7 \mathrm{MHz}$ are due to local interference. Occasional intense signals on $2.85 \mathrm{MHz}$, occurring, for example, during 17:00-18:45 UT on 5 October, result from an active ionospheric wave injection experiment conducted at the HIPAS Observatory in Chena Hot Springs, Alaska, about 50 miles away. As mentioned above, 


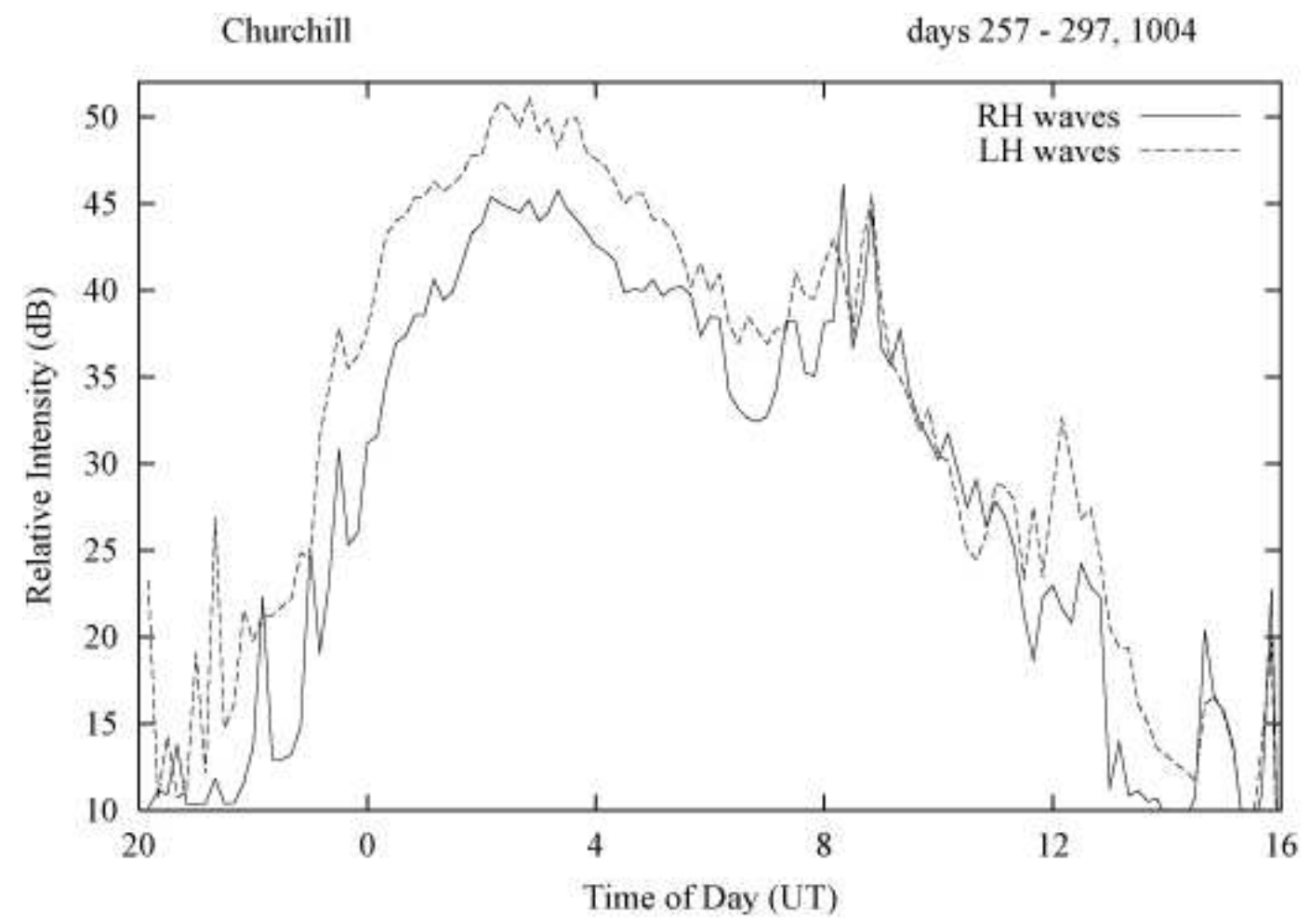

Fig. 6. Power in relative logarithmic units of left-hand (dashed trace) and right-hand (solid trace) polarized signals received at Churchill, Manitoba, integrated over the frequency range $3600-4500 \mathrm{kHz}$ and averaged over the 40-day interval from day 257 to day 297 , 1997 , as a function of time of day. During 22:00-08:00 UT and 11:00-15:00 UT, left-hand signals exceed right-hand signals by about $3 \mathrm{~dB}$; During 08:00-11:00 UT (02:00-05:00 MLT) right-hand and left-hand signals have approximately equal amplitudes. Geographic local midnight is at 06:19 UT.

the boundary between nighttime and daytime propagation characteristics is frequency dependent, with low frequency signals from distant sources fading away earlier than high frequency signals near sunrise. In addition to this effect, however, these three spectrograms show a few-dB enhancement in the intensity of received radio signals just prior to the time when they fade away at sunrise. The enhancement in the signals follows the pattern of the transition from night to day conditions, affecting first the low frequencies and later the high frequencies. On 5 October and 15 November, this enhancement sets in about $1.5-2.0 \mathrm{~h}$ before the signals fade away and lasts about an hour. On 7 October the enhancement lasts about $1-1 / 2 \mathrm{~h}$. In all three cases the magnitude of the enhancement is about $3 \mathrm{~dB}$, determined from detailed examination of the raw spectral data (not shown).

The pre-sunrise enhancement in the intensities of the signals is not common but occurs $10-30 \%$ of the time during equinox conditions at Circle Hot Springs. More examples occur during fall than during spring. Possibly, the phenomenon is hard to detect during winter and summer because the transition from day to night conditions is stunted during those seasons at high latitudes. Many examples have also been recorded at Gillam, Manitoba, the station in Canada which has magnetic latitude closest to that of Circle Hot Springs. At higher latitudes, the phenomenon appears less common; for example, no hint of it appears in Fig. 2, imply- ing that it is uncommon at Arviat. The phenomenon has only been observed at sunrise, never at sunset.

Figure 5 shows a possibly related effect occuring near the dawn terminator but involving wave polarization. The bottom panel shows a spectrogram of $50-5000 \mathrm{kHz}$ signals recorded at Churchill, Manitoba, for $20 \mathrm{~h}$, starting at 20:00 UT on 1 October 1997, a geomagnetically quiet day for which the signals show the usual diurnal pattern. Signals in the AM broadcast band at $550-1600 \mathrm{kHz}$ have been suppressed by about $10 \mathrm{~dB}$ using a mild notch filter, although the AM broadcast stations in this band dominate the received signal despite this attenuation. At Churchill during 19971998, the receiving system included two crossed antennas which were used to determine the handedness of the polarization, as described in Section 1 above. The top panel illustrates the polarization of the received signals determined by this method, with white pixels representing left-hand elliptically polarized waves and black pixels representing righthand waves. The bulk of the received signals above $1 \mathrm{MHz}$ (dark pixels above $1 \mathrm{MHz}$ in the bottom panel) correspond to predominantly left-hand polarization (white pixels in the top panel). However, an exception occurs for signals in the lower $\mathrm{HF}$ band (3-5 MHz) during appoximately 09:00-12:00 UT in the hours preceding sunrise by $1-4 \mathrm{~h}$. Under these conditions the pixels in the top panel are black, indicating predominantly right-hand polarization. 
Figure 6 shows Churchill data from a 40-day interval, days 257-297 of 1997, providing statistical evidence for this effect. The horizontal axis covers 20:00-16:00 UT, placing geographic midnight (06:19 UT) approximately in the middle of the plot. The solid trace shows the left-hand component of wave power integrated over the band $3500-4500 \mathrm{kHz}$, averaged over all 40 days, in logarithmic units. The dashed trace shows the same for right-hand waves. Signal levels increase by about $40 \mathrm{~dB}$ at nighttime, with auroral absorption greater after midnight than before midnight, in qualitative agreement with previous observations (e.g. Hunsucker et al., 1989; Greenberg and LaBelle, 2002) and models (e.g. Foppianno and Bradley, 1983). For most of the night, left-hand wave power exceeds right-hand wave power in this bandwidth by about $3 \mathrm{~dB}$, on average. However, during approximately 08:00-11:00 UT (02:00-05:00 local time), the leftand right-hand wave components are of comparable amplitude. Left-hand waves again dominate the $1-2 \mathrm{~h}$ period after this interval, until all the signals disappear at sunrise. This result holds when signals are averaged over 5-, 10-, 20-, or 60 -days. Taking longer than 60-day averages is problematic, since the sunset and sunrise times change significantly over such periods.

At least two effects can account for the predominance of left-hand polarization. The first effect is "polarization mismatch attenuation", discussed by Davies (1971). AM transmitters, which occupy the broadcast band, as well as many fixed-frequency short wave transmitters, employ vertical electric dipole antennas, implying that the radiation incident on the ionosphere is linearly polarized in the vertical plane. Consider propagation in the magnetic meridian plane, corresponding to roughly north-south propagation which is a reasonable assumption for many signals reaching the highlatitude receiver from sources far to the south: the incident wave therefore is approximately linearly polarized with its electric field vector perpendicular to the wave vector in the plane defined by the wave vector and the background magnetic field. In the ionosphere this wave must be composed of the two normal modes, $\mathrm{X}$ and $\mathrm{O}$. These modes are in general elliptically polarized in the right and left sense, respectively. Figure 7 shows the projections of these ellipses associated with the electric fields of the $\mathrm{X}$ - and O-mode, respectively, on the plane perpendicular to the wave vector for the case $X=f_{p e}^{2} / f^{2}=0.25, Y=f_{c e} / f=0.5$ and $Z=v / f=0$, as would be approximately true for a few-MHz wave incident on the ionosphere, ignoring collisions. In order to match solutions at the boundary of the ionosphere, the electric field component perpendicular to the magnetic field, the horizontal axis in Fig. 7 must vanish for all phases of the wave; hence, the Xmode ellipse must be much smaller than the O-mode ellipse, as shown in the figure. Therefore, for these parameters, a vertically polarized wave incident on the ionosphere in the magnetic meridian will convert more to O-mode than to $\mathrm{X}$ mode by about $3 \mathrm{~dB}$. The waves leaving the ionosphere on the other side then are composed with left-hand polarization exceeding right-hand polarization by about this factor, as observed. Inclusion of collisions and consideration of incident

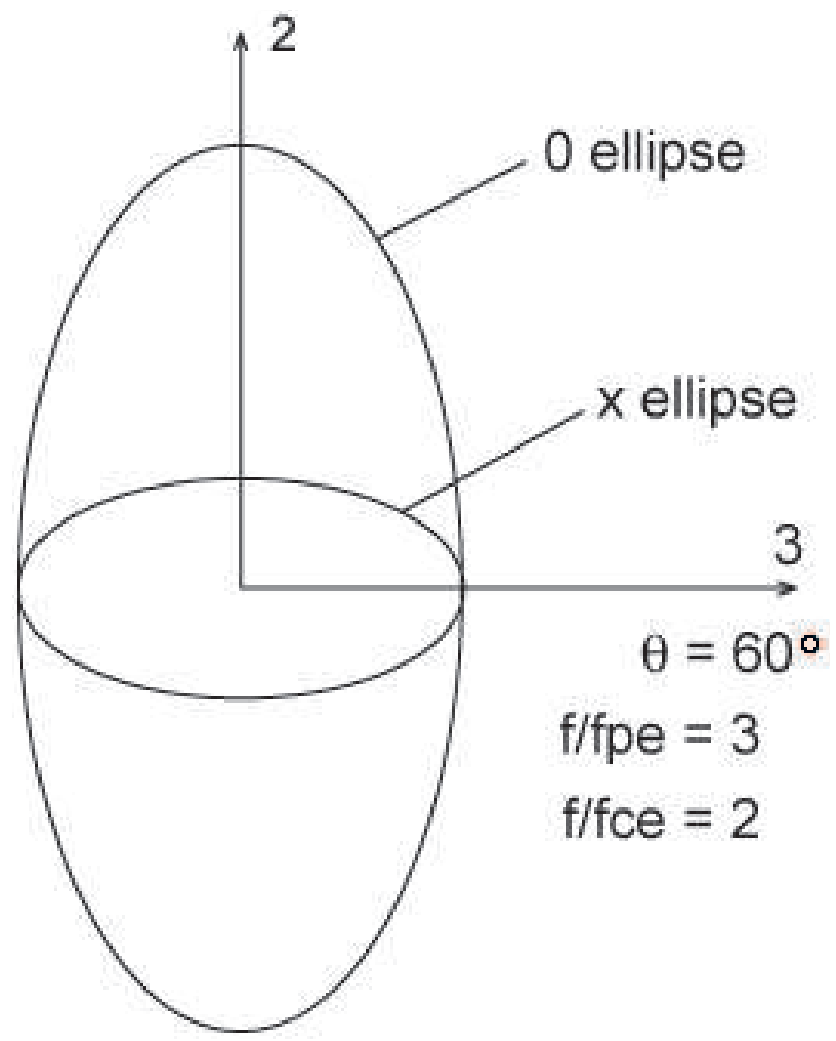

Fig. 7. The ellipses traced out by the electric field, projected into the plane perpendicular to the wave vector, for $\mathrm{O}$ - and $\mathrm{X}$-mode waves under the example conditions: $f / f_{p e}=3 ; f / f_{c e}=2 ; \theta=60^{\circ}$, where $\theta$ is the angle between the wave vector and the background magnetic field. The coordinates are so-called Davies coordinates: "1" is along the wave vector; " 2 " is perpendicular to the wave vector in the plane of the wave vector and the background magnetic field; and " 3 " is perpendicular to both the wave vector and the magnetic field. This plot shows how a vertically linear polarized wave incident on the ionosphere at high latitudes converts more to O-mode than to $\mathrm{X}$ mode.

rays outside of the magnetic meridian plane alter the calculation but do not change the basic result that left-hand waves are favored.

In addition to the polarization mismatch effect, absorption is generally greater for $\mathrm{X}$-mode propagation in the ionosphere than it is for O-mode. A spatial absorption coefficient $(\kappa)$ is straightforwardly calculated as $\omega / c$ times the imaginary part of the index of refraction obtained from the Appleton-Hartree equation. For example, for non-deviative absorption (frequencies well above the plasma frequency) and quasi-longitudinal approximation,

$\kappa \propto \frac{N v}{\left(\omega \pm \omega_{c e}\right)^{2}}$,

where the plus sign is for O-mode, and the minus sign is for $\mathrm{X}$-mode (see, for example, Eq. 23 of Dyson and Bennett, 1979, or Eq. 2.103 of Davies, 1965). Clearly, for this case of non-deviative absorption, so-called because the frequency exceeds the plasma frequency by enough so that refraction is negligible, the X-mode absorption coefficient exceeds that of 


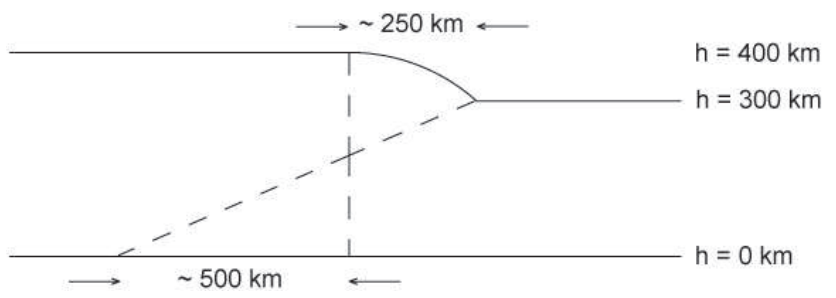

Fig. 8. Geometric optics argument for focussing of reflected signals near the dawn terminator. Supposing the dayside F-region forms first at higher altitudes (where sunrise occurs earlier) and later at lower altitudes, a beveled or curved reflecting surface might form as shown, concentrating rays on the western side of the terminator. Assuming a circular curved surface between 300 and $400 \mathrm{~km}$ extending $250 \mathrm{~km}$ horizontally implies $3 \mathrm{~dB}$ enhancement of power over a $500 \mathrm{~km}$ extent west of the terminator $(20 \mathrm{~min}$ in local time preceding sunrise).

O-mode due to the term in the denominator. Since the former is right-hand elliptically polarized in general, while the latter is left-hand polarized (or linearly polarized in the extreme case of perpendicular propagation), the expected result is that the right-hand component is in general more absorbed. Physically, this results because the electron revolves around the field line in the same sense as the electric field for the $\mathrm{X}$-wave, but in the opposite sense for the $\mathrm{O}$-wave.

The several-hour long interval after midnight, when righthand waves are received with approximately equal amplitude as left-hand waves, is difficult to explain. Possibly this effect indicates that deviative rather than non-deviative absorption is significant for these local times. The absorption during the post-midnight hours distinctly exceeds that during the premidnight hours, as seen in Fig. 5, and also confirmed by statistical data and empirical models of auroral absorption (see Foppianno and Bradley, 1983; Milan et al., 1996; Greenberg and LaBelle, 2002) Deviative absorption requires full-wave theory and an ionospheric model to calculate, and it depends on spatial gradients of the refractive index along the ray path. It is possible that for certain combinations of ray paths the deviative absorption of O-mode could exceed that for X-mode, since the two modes follow different ray paths in the ionopshere. Calculations of deviative absorption are beyond the scope of this paper, but the repeatability of the excess righthand polarization in the post-midnight hours for lower HF propagation indicates that further study and modeling of the deviative absorption is warranted.

An alternative hypothesis to explain the apparent observation of comparable amounts of right- and left-hand polarization in the post-midnight hours is that the experimental method, involving phase difference measurements between two perpendicular vertically-oriented magnetic loop antennas, is sensitive to the direction of arrival, as well as the handedness of the polarization, especially when the signals arrive from low elevation angles. At the extreme of zero degrees elevation angle, the signals on the crossed magnetic loops are either in-phase or $180^{\circ}$ out-of-phase on the two antennas, depending on the azimuth of arrival, and in either case, the experimental method registers equal left-hand and righthand components. Hence, at low elevation angles, a shift to an even lower elevation angle could masquerade as a shift towards more equal amounts of left- and right-hand polarizations. However, this instrumental effect cannot explain cases such as that illustrated in Fig. 5, in which the polarization switches from left-hand to right-hand. Also, it begs the question of why a consistent shift to lower elevation angles would occur during the post-midnight period. Perhaps precipitation patterns tend to produce reflection from a lower layer than during pre-midnight hours.

The enhancement in the signals just before dawn, shown in Fig. 4, resembles a similar effect observed by Davies (1965) on LF frequencies, illustrated by his Fig. 9.22 which shows an $\sim 6-\mathrm{dB}$ increase in the intensity of $200 \mathrm{kHz}$ signals just after sunset and before sunrise. These are low-latitude observations and suggest a phenomenon occuring at both sunset and sunrise. Nevertheless, they may be related to the pre-sunrise enhancements in the signals received at high latitudes. Brown (1998) also describes sunrise effects on ionospheric propagation of LF waves. Davies (1965) attributes the highly variable LF propagation characteristics just before dawn to interference between propagation modes near the terminator: if, for example, nighttime signals are received via reflection from the E-region, these signals are strongly attenuated because of the low elevation angle and hence long traversal distance in the absorbing D-layer. Well before ground-level sunrise, illumination of the F-region causes a second reflection layer for which the elevation angle is steeper, the traversal distance within the D-region is smaller, and the resulting attenuation is smaller. With sunrise at Dregion altitudes, strong absorption attenuates all the signals. This model would predict an intensification just before sunrise. At F-region heights sunrise takes place about $30 \mathrm{~min}$ before sunrise at D-region heights, so the effect would last the order of half an hour.

Another possible explanation would involve focussing of reflected signals near the terminator. By analogy to ray optics, consider rays reflecting specularly off of the F-layer to reach the receiver from distant sources $>1500 \mathrm{~km}$ south. Before sunrise the F-region has settled into a stable position whereby the reflection is analogous to that from a flat mirror. Sunrise affects the high altitudes first, with sunrise at $300 \mathrm{~km}$ occurring $8-10 \mathrm{~min}$ after sunrise at $400 \mathrm{~km}$. On occasion a reflecting layer effectively curved in the east-west direction may result over a horizontal distance comparable to the distance the Earth rotates in 8-10 min, or about $250 \mathrm{~km}$. Rays striking this surface would be reflected onto non-greatcircle paths which would direct them to the west, leading to a focussing of the energy in a region hundreds of kilometers wide. Figure 8 shows this situation schematically. For the shape of the underside of the F-region illustrated there, ray optics predicts about a $3-\mathrm{dB}$ enhancement over a region $500 \mathrm{~km}$ west of the terminator, roughly in agreement with the data. For north-south propagation, this effect would be favorably observed near equinox, when the terminator is aligned with the north-south direction. For this model, the predicted 
characteristics of received signals obviously depend sensitively on the shape of the underside of the F-region at the terminator.

\section{Magnetic storm and substorm effects}

There is a wealth of literature pertaining to the effects of magnetic storms and substorms on ionospheric propagation, dating back to the earliest years of radio science. With regard to magnetic storm related effects, the principal phenomenon is "Polar Cap Absorption" (PCA), readily identified as enhanced absorption in riometer or ionosonde data but also as a black-out of ionospheric propagation on $\mathrm{LF} / \mathrm{MF} / \mathrm{HF}$ in polar regions, caused by absorption due to enhanced ionization in the lower ionosphere, caused by bombardment of the polar cap ionosphere by $\sim 10 \mathrm{MeV}$ solar energetic protons following a solar flare. Hunsucker and Bates (1969) reviews the copious early literature on this $\mathrm{LF} / \mathrm{MF} / \mathrm{HF}$ propagation phenomenon. More recent examples include: observations on MF by Hunsucker et al. (1989) showing ionospheric paths Kotzebue-Fairbanks and San Francisco-Fairbanks that were wiped out for 3 and 8-9 days, respectively, during a May 1986 magnetic storm; and storm-associated decreases in received HF signals quantitatively analyzed by Milan et al. (1998). In addition to these well-documented decreases in LF/MF/HF ionospheric propagation during storms, superposed-epoch analysis of IGYera observations provides evidence of an increase in amplitude of received ionospheric propagating HF signals at 20$25 \mathrm{MHz}$ during approximately $12 \mathrm{~h}$ prior to magnetic storm sudden commencements (Ondoh et al., 1964; Ondoh and Obu, 1965).

The association between ionospheric propagation and auroral substorms appears even more complex. As shown above (Fig. 2) and in many other references, the principal effect of auroral substorms is black-out of ionospheric propagation at LF/MF/HF locally immediately following substorm onset, until after a recovery period of the order of tens of minutes to hours, a phenomenon known as substormcorrelated absorption (e.g. review by Hunsucker, 1992; LaBelle et al., 1994; Milan et al., 1996; Blagoveshensky and Borisova, 2000). For example, Milan et al. (1996) show enhanced absorption of the order of $\sim 30 \mathrm{~dB}$ on $6.8 \mathrm{MHz}$ associated with individual magnetic substorms, and investigate a correlation between the magnitude of the absorption and the degree of dipolarization associated with each substorm. Direction finding studies show large deviations in arrival bearing associated with ionospheric propagating HF signals during auroral activity (Rogers et al., 1997; Warrington et al., 1997), a signature of non-great-circle propagation (review by Hunsucker and Bates, 1969). Furthermore, as noted above, enhanced ionospheric propagation can be associated with auroral substorms due to the formation of an auroral sporadic E-layer supporting additional propagation modes with low absorption (e.g. Hunsucker and Bates, 1969; Hunsucker et al., 1996; Milan et al., 1997). Also, a number of stud- ies indicate increases in HF ionospheric propagation preceding substorms; for example, Blagoveshensky and Vystavnoy (1994) observe enhancement of ionospheric propagation on 15-25 MHz 3-4 h preceding substorm onset, and Blagoveshensky and Borisova (2000) observe enhancement in ionospherically propagating HF signals associated with growth phase of substorms, $1-2 \mathrm{~h}$ prior to substorm onset, followed by the usual sharp decrease in ionospherically propagating HF signals at onset. A number of empirical and semiempirical models attempt to incorporate these complex observations, as reviewed by Hunsucker (1992), including, for example, the DIAS model (Rose, 1993) and the Foppiano-Bradley model (Foppianno and Bradley, 1983), the latter tested in two recent experimental studies (Milan et al., 1996; Greenberg and LaBelle, 2002). Recently, Greenberg and LaBelle (2002) completed an extensive study of substorm-correlated absorption in which they used passive measurements of radio-wave absorption on large numbers of subionospherically propagating HF transmissions to confirm the Foppianno and Bradley (1983) auroral absoption model.

As mentioned above, Fig. 3 shows that intervals when the planetary K-index is elevated for several consecutive days, such as during magnetic storms, severe disruptions and polar cap absorption affect over-the-horizon HF radio communications in the polar regions. Figure 9 shows the time history of a PCA event associated with two major solar $\mathrm{x}$-ray flares: one at 05:54 UT on 4 November 1997, and the other at 11:54 UT on 6 November 1997. Coronal Mass Ejections (CMEs) and interplanetary shock waves accompanied each of these flares; the shock waves reached the Earth about 2-1/2 days after each flare. Figure 9 combines radio spectra recorded simultaneously at five high-latitude observatories ranging from Gillam ( $66^{\circ}$ invariant) in the south to Taloyoak ( $79^{\circ}$ invariant) in the north. From each observatory, the received power integrated over the frequency range $3.5-4.5 \mathrm{MHz}$ is normalized to a "quiet day" level, and by interpolation this normalized integrated power is obtained as a function of magnetic latitude between $66^{\circ}$ and $79^{\circ}$. In Fig. 9 the x-axis represents nine days between 3 November and 12 November, the y-axis represents invariant latitude ranging from $67^{\circ}$ to $79^{\circ}$, and the gray scale represents the received power integrated over the 3.5-4.5 MHz band, divided by the "quiet day" value of the same parameter, with black pixels representing $40 \mathrm{~dB}$ higher ratio than white pixels. Only nighttime data are shown, roughly 00:00-12:00 UT, and white vertical bands indicate the data gaps when daytime data are not shown. Arrows indicate the times of the two solar flares which were accompanied by CMEs.

At the time of the first solar flare, 05:54 UT on 4 November, strong absorption sets in promptly at latitudes above 68 degrees, with weaker absorption or no absorption at lower latitudes. Over the next 2-1/2 nights the received power remains low at high latitudes but begins to recover at low latitudes, with the cutoff in attenuation rising from about $69^{\circ}$ to about $71^{\circ}$. The second solar flare hits during daytime, but data from the following night show that the absorption has expanded to lower latitudes, extending below $67^{\circ}$, the 


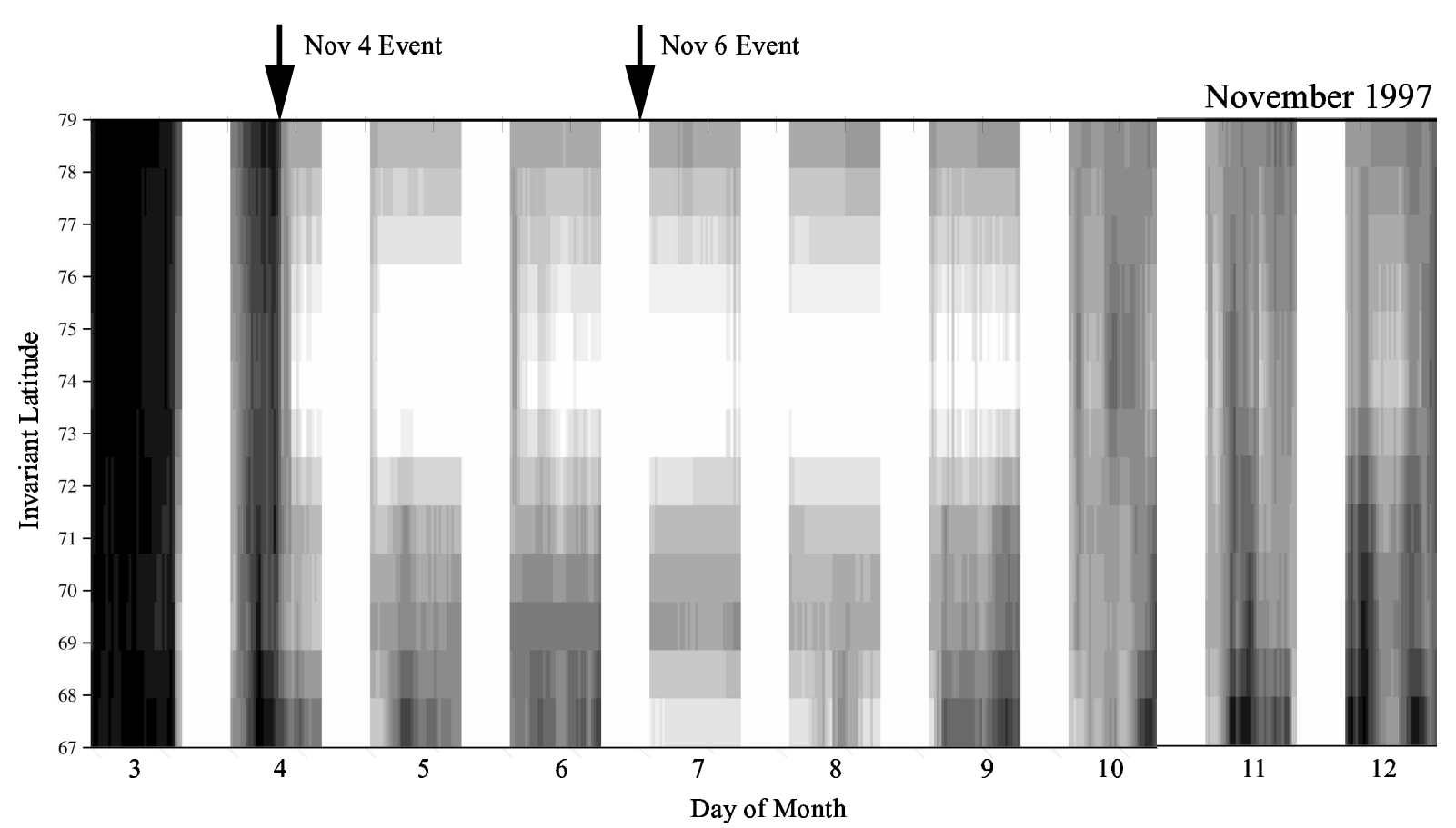

Fig. 9. Received signal power integrated over the frequency range 3.5-4.5 MHz, normalized to the same parameter measured on a quiet day, as a function of invariant longitude based on data from five observatories spanning $67-79^{\circ}$. Only nighttime data are shown, vertical white bands indicate the data gaps corresponding to daytime, and black pixels indicate a ratio $40 \mathrm{~dB}$ above that indicated with white pixels. Arrows indicate the times of solar flares accompanied by CMEs on 4 and 6 November 1997.

lowest latitude covered by the meridional chain of radio receivers. Over the next three nights, normal propagation conditions gradually return, starting at the lowest latitudes and shifting poleward; by 10 November conditions over the entire $67-79^{\circ}$ invariant latitude range have essentially returned to normal. These recovery times are typical of those reported for many previous PCA's (e.g. May 1986 storm analyzed by Hunsucker et al., 1989).

Instruments on board the SAMPEX satellite in highinclination low-Earth orbit measured the enhanced $\mathrm{MeV}$ proton fluxes associated with these solar flares. Prompt increases occur at the times of each flare, which recover over a time period of a couple of days (see Fig. 1 of Mazur et al., 1999). The 6 November flare causes an order of magnitude higher flux of $19-27 \mathrm{MeV}$ protons than does the 4 November flare, and the flux takes correspondingly longer to recover. To within the uncertainty implied by the twelve-hour gaps in the radio data, the data are consistent with the hypothesis that the enhanced proton fluxes cause the prompt absorption features detected with the meridional chain of radio receivers, with the 6 November event, characterized by larger proton flux, causing radio-wave absorption over a wider range of geomagnetic latitudes. On 4 November the enhanced proton flux detected by SAMPEX coincides with the onset of radio-wave absorption. On 6 November, the enhancement in proton flux occurs during the gap in radio data, and the arrival at Earth of the CME-related shock wave from the 4 November event occurs within the first hour after nighttime radio-wave propagation conditions are re-established; since the radio-wave data show strong absorption from the start of the evening, this observation strongly suggests that the enhancement in the protons rather than the arrival of the shock wave causes the expanded radio-wave absorption.

SAMPEX also provides information about the latitude of penetration of the energetic protons, which can be estimated with approximately hourly time resolution by measuring the L-shell at which the protons turn off twice per SAMPEX orbit (B. Blake, personal communication, 2000; Mazur et al., 1999). The SAMPEX data show that the boundary of the energetic protons shifts to lower latitudes not immediately after the flare, but $21 / 2$ days later when the resulting shock wave hits the Earth's magnetopause and compresses it, allowing particles of a given rigidity access to lower latitudes. For example, upon arrival of the first shock wave at Earth at about 00:00 UT on 7 November, the cutoff for $19-28 \mathrm{MeV}$ protons shifts from about $63^{\circ}$ to about $58^{\circ}$ invariant latitude, then recovers fairly rapidly within about 24 hours (see Fig. 2 of Mazur et al., 1999). As mentioned above, the data strongly suggest that the onset of radio absorption at low latitudes (Fig. 9) is associated with the initial flare/CME, not with the arrival of the shock wave, though this result is subject to uncertainty because the shockwave arrival occurs just barely after the onset of nighttime conditions in the Churchill meridian on 6-7 of November. The SAMPEX data show a similar short-duration shift in the energetic proton boundary on 9 November. No radio absorption feature occurs at this time, although by 9 November the energetic proton flux has relaxed to the point at which the absorption effects would 

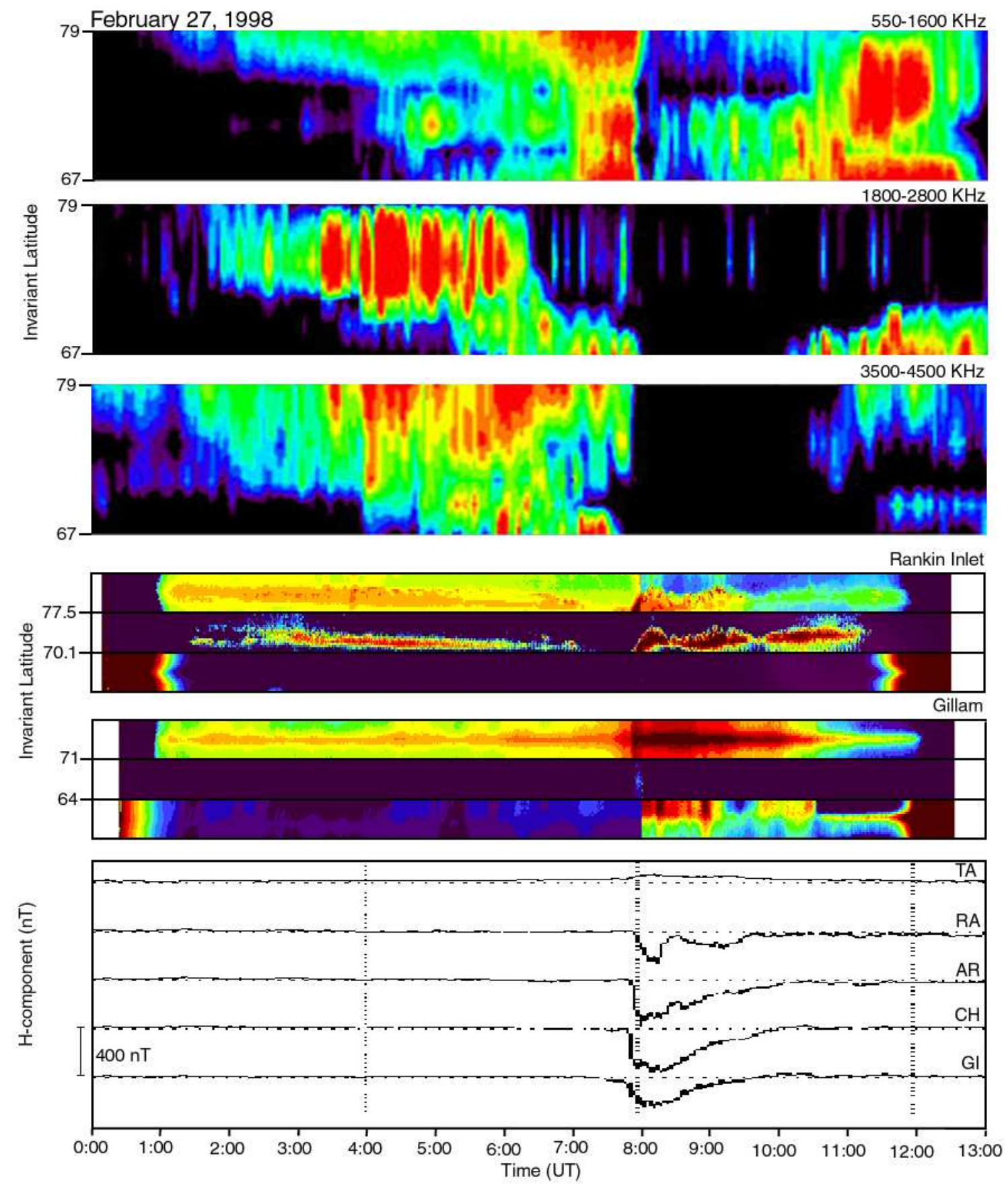

Fig. 10. (a) Radio-wave power received at five observatories in Northern Canada, integrated over the frequency range $3.5-4.5 \mathrm{MHz}$ and normalized to quiet day values, plotted as a function of invariant latitude for 00:00-13:00 UT on 27 February 1998. (b) The same for the frequency range $1.8-2.8 \mathrm{MHz}$. (c) The same for the frequency range $0550-1600 \mathrm{kHz}$. (d) Meridian scanning photometer (MSP) recorded at Rankin Inlet (near Baker Lake) in three wavelengths: 5577 AA (top panel), 4861 AA (middle panel), and 4800 AA (bottom panel), each covering the latitude range $70.1-77.5^{\circ}$. (e) Similar MSP data recorded at Gillam, covering the latitude range $64-71^{\circ}$. (f) $\mathrm{H}$-component of the Earth's magnetic field measured at five CANOPUS sites spanning 67-79 ${ }^{\circ}$ invariant latitude.

be hard to detect. For the relatively crude latitude resolution of these data, consisting of only five stations covering 13 degrees of latitude, these data from two solar flares with CMEs suggest that the latitudinal extent of the radio-wave blackout responds primarily to the flux level of the energetic protons initially arriving at Earth, with the larger proton flux resulting in blackout over a wider latitude range, rather than reflecting the shift in the latitude of penetration of those protons which occurs when the shock wave reaches the Earth and compresses the magnetosphere. This result supports the statement on p. 352 of Hunsucker and Bates (1969) that "the boundary of the absorbing regions moves equatorward with increasing event magnitude". 

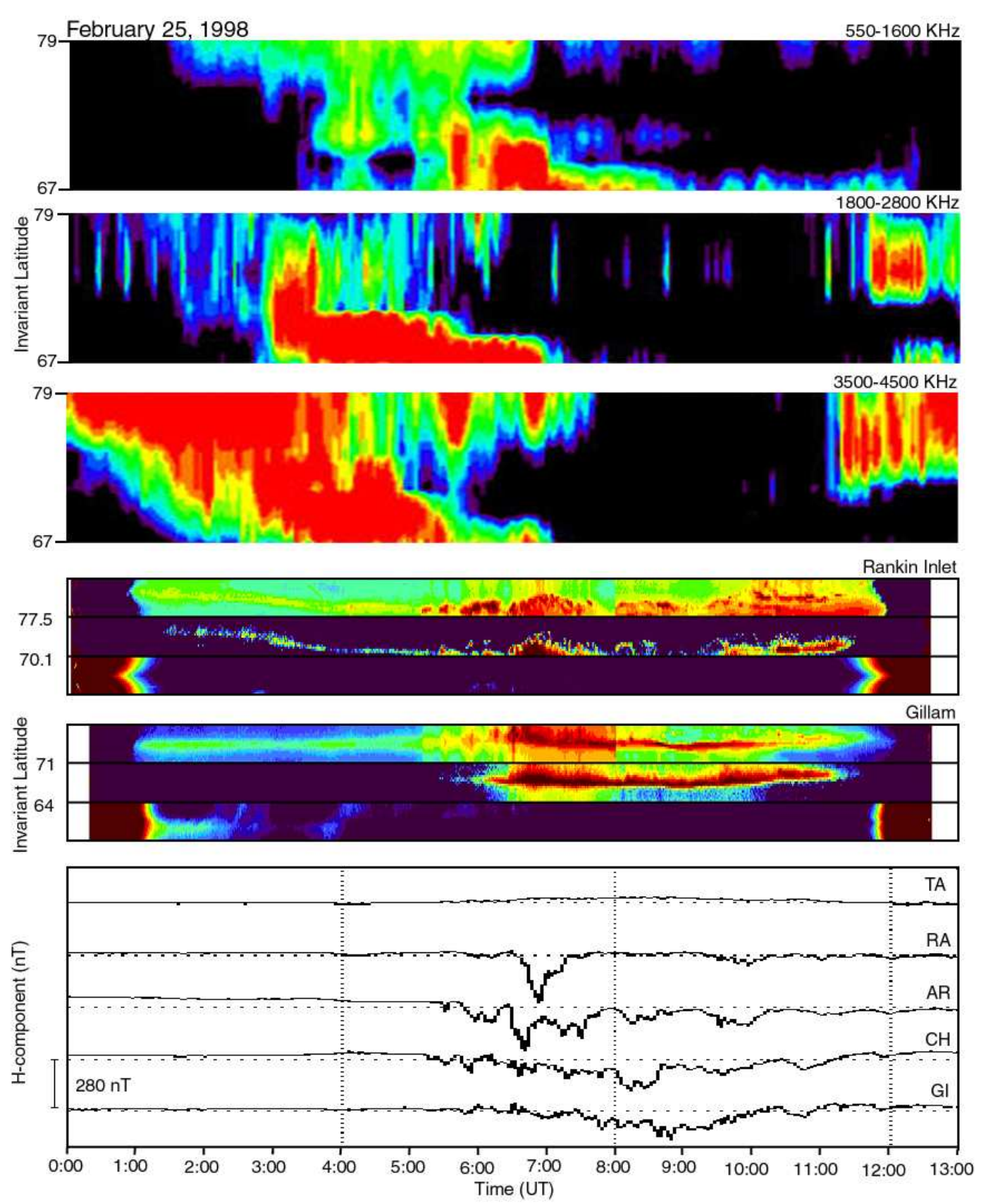

Fig. 11. Data from 00:00-13:00 UT on 25 February 1998, in the same format as Fig. 10.

In addition to tracking the latitude dependence of auroral absorption over several days during magnetic storms, the meridional chain of radio receivers effectively measures spatial and temporal variations in radio-wave propagation conditions associated with substorms over shorter intervals, albeit with relatively crude latitude resolution implied by five observatories covering 13 degrees of latitude. Figure 10 shows data from 00:00-13:00 UT on 27 February 1998, when a relatively isolated substorm onset occurred in the Northern Canada sector just before 08:00 UT. The top three panels show the integrated power in three frequency bands as a function of invariant latitude from $67^{\circ}$ to $79^{\circ}$, normalized to quiet day conditions: $3500-4500 \mathrm{kHz}$ (top panel), $1800-2800 \mathrm{kHz}$ (second panel), and $0550-1600 \mathrm{kHz}$ (third panel). The color scale spans $30 \mathrm{~dB}$ in the ratio of integrated power to the quiet day value. This last selected band corresponds almost entirely to AM broadcast band transmissions. The other two selected bands correspond to a mix of signals of man-made and natural origin, though man-made signals generally dominate, especially in the HF band $(3500-4500 \mathrm{kHz})$. The panels below the radio-wave data show meridian scanning photometer (MSP) data from Rankin Inlet (near Baker Lake) and Gillam, for three selected wavelengths: 5577 AA (top panel for each site), $4861 \mathrm{AA}$ (middle panel for each site), and $4800 \mathrm{AA}$ (bottom panel for each site). At Rankin Inlet, all three panels span the latitude range $70.1-77.5^{\circ}$, and at Gillam, all three 
panels span the latitude range $64-71^{\circ}$. The bottom panels of Fig. 10 show the H-component of the geomagnetic field measured at five CANOPUS sites along the meridional chain. Bays in the magnetometer traces indicate the substorm onset at 07:56 UT. The growth phase is characterized by southward motion of the auroral arc, as observed in the 4861 AA MSP keogram from Rankin Inlet. The Gillam MSP data are affected by cloud cover on this date, though they clearly show the 07:56 UT substorm onset.

Interestingly, the radio propagation data show evidence for a southward shift in the radio propagation characteristics preceding the substorm, simultaneous with the southward motion of the auroral arc. This effect is most evident in the Fig. 10b (corresponding to $1800-2800 \mathrm{kHz}$ ), in which a band of latitudes of favorable propagation conditions appears to shift to lower latitudes during approximately 05:0008:00 UT, three hours before the substorm onset; in the other two frequency bands, favorable propagation conditions also appear to expand to lower latitudes during the same interval. The substorm onset is clearly visible as a prompt onset of substorm-corellated absorption over all frequency ranges just before 08:00 UT, with gradual recovery one to two hours later.

The spatial variations in radio propagation characteristics preceding the substorm onset imply that the growth phase of the substorm may be associated either with enhanced signals reaching the receiver in the hour before substorm onset, or with decreased signals reaching the receiver, depending on the latitude of the observations and the frequency band being observed. These data highlight the complexity of identifying substorm effects on radio-wave propagation: to correctly interpret radio signatures preceding the substorm onset requires a chain of observatories. Figure 11 shows data from 00:00-13:00 UT on 25 February 1998, in the same format as Fig. 10. On this day, as on 27 February, a dramatic southward shift of the band of latitudes of favorable propagation conditions coincides with the southward motion of the auroral arc preceding 07:00 UT. In this case the substorm onset is not as well defined in the radio propagation data as it was on 27 February, because several small pseudo-breakups precede the final substorm onset. However, all three selected frequency ranges show clearly the southward shift in propagation characteristics during the hours preceding substorm onset near 07:00 UT.

To estimate what fraction of auroral activations show such latitudinal shifts in ionospheric propagation conditions, CANOPUS magnetometer data from 1 April 1997 to 31 March 1998 have been used to identify 103 "isolated" magnetic bays, defined as a decrease of at least $150 \mathrm{nT}$ in the $\mathrm{H}$-component of the geomagnetic field within a 20 -min interval at one or more site along the Churchill meridian, with no decreases of greater than $100 \mathrm{nT}$ occuring during the previous three hours. In about one-quarter of these cases, the radio data were of insufficient quality or quantity to identify a latitudinal structure. However, half of the remaining events showed evidence for southward motion or southward expansion of the latitude range of favorable radio propaga- tion conditions $1-3 \mathrm{~h}$ preceding the magnetic bay. During some of the other events, the effect may occur but is hard to discern because the magnetic bays are not sufficiently isolated. Spatial variations of radio-wave propagation characteristics preceding substorm onsets reflect patterns of precipitation and associated ionospheric conductivity and have implications for models of substorms, for example, by providing supporting evidence for enhanced ionization over a wide region preceding substorm onsets (as put forth by Lessard and Lotko, 2003). Tracking substorm growth phase and onset with radio propagation data has the advantage of being inexpensive, based on passive measurements from a few sites, and effective even when cloudy skies make ground-based optical observations impossible.

\section{Conclusions}

The effects discussed above occur primarily on time scales of an hour or more, associated with day-night transition, magnetic storms, or substorms. Besides these, many shorter time scale ionospheric effects are detectable in LF/MF/HF radio propagation data at multiple high-latitude sites. For example, received radio signals of both man-made and natural origin are often modulated with periods of a few minutes during times of local auroral and geomagnetic activity, and such modulations are sometimes correlated with modulations in the optical aurora and with geomagnetic pulsations. For another example, spectra of broad-band signals, such as atmospherics, propagating to a high-latitude radio receiver over long distances, sometimes exhibit low-frequency cutoffs, with the cutoff frequency varying on time scales from seconds to tens of minutes. These features reflect short time scale variations in the auroral ionosphere during auroral activity but are beyond the scope of this report which concentrates on phenomena associated with larger scale features, such as day-night transitions, magnetic substorms, and magnetic storms.

Historically, active vertical and oblique sounding experiments have played the biggest role in characterizing LF/MF/HF radio-wave propagation. However, passive monitoring of LF/MF/HF spectra over a wide frequency range at multiple high-latitude sites provides a complementary perspective and reveals many patterns in propagation characteristics, some of them easily interpreted in terms of basic ionospheric physics but others more subtle, not previously reported, and not readily explained. Among these features are: persistent slight enhancements in LF/MF/HF signals just before dawn; variations in the polarization or direction of arrival of LF/MF/HF signals as a function of time of day, inferred from the phase difference between signals received on crossed antennas; the latitude extent of the blackout of subionospherically propagating LF/MF/HF signals following large solar flares; and persistent patterns in the latitudinal variation of radio propagation characteristics at high latitudes preceding and following substorm onsets. These features are repeatable night-to-night and season-to-season, so investigations toward explaining them are warranted and may shed 
further light on the ionospheric reaction to auroral activity, with implications for ionosphere-magnetosphere interactions and theories of substorms.

Acknowledgements. The author is indebted to K. Davies, M. Trimpi, R. Brittain, G. Reid, and A. Weatherwax for helpful discussions related to this work. Many undergraduate students contributed to the data analysis, including M. Giger, P. Faurot-Pigeon, A. Crocker, and E. Greenberg. The role of the operators at the remote observatories is also greatly appreciated, including D. Foster and R. Drouin at Circle Hot Springs, the late E. Thompson at Fairbanks, D. St Jacques at Gillam, the late R. King at Arviat, R. Mannilaq at Taloyoak, contractors of the Canadian Geological Survey at Baker Lake, and the staff of the Churchill Northern Studies Centre at Churchill, Manitoba. The author is also grateful to the CANOPUS science team for permission to use their magnetometer and photometer data. This research was supported by the United States National Science Foundation grant ATM-0243595 to Dartmouth College.

Topical Editor M. Lester thanks A. Stocker and D. Blagoveshchensky for their help in evaluating this paper.

\section{References}

Blagoveshensky, D. V. and Borisova, T. D.: Substorm effects of ionosphere and HF propagation, Radio Sci., 35, 1165-1171, 2000.

Blagoveshensky, D. V. and Vystavnoy, V. M.: Oblique-incidence sounding of the high latitude ionosphere, accounting for a new parameter, signal intensity, Geomag. Aeron., 33, 710-714, 1994.

Brown, R. R.: Unusual LF signal propagation at sunrise, Communications Quarterly, Fall 1998, 67-82, 1998.

Davies, K.: Ionospheric radio propagation, NBS Monograph 80, Washington, 1965.

Davies, K.: Ionospheric radio, Peregrinus, London, 1971.

Dyson, P. L. and Bennett, J. A.: General Formulae for absorption of radio waves in the ionosphere, J. Atmos. Terr. Phys., 41, 1979.

Foppianno, A. J. and Bradley, P. A.: Prediction of auroral absorption of high-frequency waves at oblique incidence, Telecomm. J., 50, 547-560, 1983.

Greenberg, E. M. and LaBelle, J.: Measurement and modeling of auroral absorption of HF radio waves using a single receiver, Radio Sci., 37, doi:10.1029/2000RS002 550, 2002.

Hunsucker, R. D.: Auroral and polar cap effects on radio propagation, IEEE Proc. Antennas Propag., 40, 818-828, 1992.

Hunsucker, R. D. and Bates, H. F.: Survey of polar and auroral region effects on HF propagation, Radio Sci., 4, 347-365, 1969.

Hunsucker, R. D., Delana, B. S., and Wang, J. C. H.: Propagations characteristics of MF skywave signals from the continental US and Canada received at Fairbanks, Alaska, AGARD Conf Proceedings 382: Propagation effects on military systems in the high latitude region, pp. 3.4-1, NATO, 1985.

Hunsucker, R. D., Delana, B. S., and Wang, J. H. C.: Medium frequency skywave propagation at high latitudes: Results of a fiveyear study, IEEE Trans. Broadcasting, 35, 218-222, 1989.

Hunsucker, R. D., Rose, R. B., Adler, R. W., and Lott, G. K.: Auroral-E mode oblique HF propagation and its dependence on auroral oval position, IEEE Proc. Antennas Propag., 44, 383388, 1996.

LaBelle, J. and Treumann, R. A.: Auroral Radio Emissions, 1. Hisses, Roars, and Bursts, Space Sci. Rev., 101, 295-440, 2002.
LaBelle, J. and Weatherwax, A. T.: Ground-based observations of $\mathrm{LF} / \mathrm{MF} / \mathrm{HF}$ radio waves of auroral origin, in physics of space plasmas, edited by Chang, T., p. 223, Scientific Publishers, Cambridge, 1992.

LaBelle, J., Weatherwax, A. T., Trimpi, M. L., Brittain, R., Hunsucker, R. D., and Olson, J. V.: The spectrum of LF/MF/HF radio noise at ground level during substorms, Geophys. Res. Lett., 21, 2749-2752, 1994.

Lessard, M. and Lotko, W.: The development of parallel electric fields during substorm growth phases as a result of differential particle mirroring, American Geophysical Union, Fall meeting 2003, abstract \# SM4213-063, 2003.

Mazur, J. E., Mason, G. M., Looper, M. D., Leske, R. A., and Mewaldt, R. A.: Charge states of solar energetic particles using the geomagnetic cutoff technique: SAMPEX measurements in the 6 November 1997 Solar particle events, Geophys. Res. Lett., 26, 173-176, 1999.

Milan, S. E., Jones, T. B., Lester, M., Warrington, E. M., and Reeves, G. D.: Substorm correlated absorption on a $3200 \mathrm{~km}$ trans-auroral HF propagation path, Ann. Geophys., 14, 182-190, 1996.

Milan, S. E., Jones, T. B., and Warrington, E. M.: Enhanced MUF propagation of HF radio waves in the auroral zone, J. Atmos. Solar Terr. Phys., 59, 237-248, 1997.

Milan, S. E., Lester, M., Jones, T. B., and Warrington, E. M.: Observations of the reduction in the available HF band on four high latitude paths during periods of geomagnetic disturbance, J. Atmos. Solar Terr. Phys., 60, 617-629, 1998.

Ondoh, T. and Obu, K.: Studies on Pre-SC ionosphere and HF radio propagation over polar paths: II, Pre-SC increase of WWV 20 and $25 \mathrm{MHz}$ field intensity and of f0F2 in high latitudes, J. Geomag. Geoelectr., 17, 45-57, 1965.

Ondoh, T., Obu, K., and Takenoshita, Y.: Studies on Pre-SC ionosphere and HF radio propagation over polar paths: I, Pre-SC increase of WWV MHz received at Hiraiso, Japan, J. Geomag. Geoelectr., 16, 201-209, 1964.

Reid, G. C.: A study of the enhanced ionization produced by solar protons during a polar cap absorption event, J. Geophys. Res., 66, 4071, 1961.

Reid, G. C.: Ion chemistry in the D-region, in advances in atomic and molecular physics, 14, edited by Baets, D. R. and Bederson, D. R., pp. 375-413, Academic, San Diego, 1976.

Rishbeth, H. and Garriott, O. K.: Introduction to ionospheric physics, Academic Press, New York, 1969.

Rogers, N. C., Warrington, E. M., and Jones, T. B.: Large HF bearing errors for propagation paths tangential to the auroral oval, IEEE Trans. Microw. Antennas Propag., 144, 91-96, 1997.

Rose, R. B.: A high latitude ionospheric disturbance impact system, Radio Sci., 28, 97-104, 1993.

Shepherd, S. G., LaBelle, J., and Trimpi, M. L.: The polarization of auroral radio emissions, Geophys. Res. Lett., 24, 3161, 1997.

Warrington, E. M., Rogers, N. C., and Jones, T. B.: Large HF bearing errors for propagation paths contained within the polar cap, IEEE Trans. Microw. Antennas Propag., 144, 241-249, 1997.

Weatherwax, A. T.: Ground-based observations of auroral radio emissions, Ph.D. thesis, Dartmouth College, Hanover, N. H., 1994.

Weatherwax, A. T., LaBelle, J., Trimpi, M. L., Treumann, R. A., Minow, J., and Deehr, C.: Statistical and case studies of radio emissions observed near $2 f_{c e}$ and $3 f_{c e}$ in the auroral zone, J. Geophys. Res., 100, 7745, 1995. 